\title{
An evaluation of the effectiveness of the Injury Minimization Programme for Schools (IMPS)
}

Katrina Frederick, Elizabeth Bixby, Marie-Noelle Orzel, Sarah Stewart-Brown, Keith Willett

\begin{abstract}
Objective-To evaluate the effect of an injury prevention programme (Injury Minimization Programme for Schools, IMPS) on children's primary and secondary prevention, and basic life support, knowledge, attitudes, skills, and behaviour.

Design-Prospective non-randomised matched control.

Setting-Radcliffe NHS Trust and primary and middle schools in Oxfordshire, UK.

Subjects-1200 year 6 children (10 and 11 years old); 600 received IMPS, a primary and secondary injury prevention programme taught in the school and hospital environments; 600 children in the control group received no planned intervention.

Main outcome measures-Safety knowledge, measured using a quiz. Resuscitation skills and behaviour observed and assessed using a simulated emergency scenario. Attitude and hypothetical behaviour towards safety assessed by the "draw and write" technique.

Results-Before intervention, both groups had similar levels of knowledge. Five months after the intervention, significantly more IMPS trained children demonstrated a greater increase in knowledge in administering first aid and the correct procedure for making a call to the emergency services. They also demonstrated better basic life support techniques-for example, mouth-to-mouth and cardiac compressions. They identified more subtle dangers, were more likely to seek help, and tell others that their behaviour was dangerous.

Conclusion-The results demonstrate the benefits of the IMPS programme on injury prevention knowledge, attitudes, and behaviours.

(Injury Prevention 2000;6:92-95)
\end{abstract}

John Radcliffe

Hospital, Oxford, UK K Frederick

E Bixby

M-N Orzel

S Stewart-Brown

K Willett

Correspondence to: Katrina Frederick, Room 4, Manor House, John Radcliffe Hospital, Headley Way, Headington, Oxford OX3 9DU, UK (e-mail: kate.frederick@ orh.anglox.nhs.uk) as one of the five key areas to be reduced over the next 10 years. Among children and young adults injuries continue to be the leading cause of death. ${ }^{23}$ It has been suggested that the number of injury deaths may be reduced and the extent of an injury minimised if children are equipped with appropriate skills and knowledge. ${ }^{4}$ Recent studies identify schools as an ideal environment for learning about how to prevent injuries or reduce the consequences of an injury. ${ }^{67}$

The Injury Minimization Programme for Schools (IMPS) began in 1994. By the end of the 1998-99 school year, approximately 7500 children will have completed the programme. To determine its effectiveness, a structured evaluation was completed to determine the extent to which it changes a child's knowledge, attitudes, and behaviour, and the extent to which improvements in knowledge and skills are retained.

\section{Subjects and methods}

THE INTERVENTION

IMPS was developed in Oxford by a group of health care professionals in response to the then Health of the Nation (1992) recommendations. ${ }^{8}$ The programme targets 10-11 year old children (year 6) and is delivered within the school curriculum. Children are taught about risks and the possible outcomes if they choose to take those risks. In addition they are given the skills and knowledge to enable them to minimise the impact of an injury. IMPS is delivered both in schools and in hospitals, and focuses on the following areas: road safety, accidents in the home, fire, electricity, poisons, and waterways. Teachers are provided with an IMPS education resource pack. The pack provides extensive teaching materials that explore all aspects of risks and safety. The school programme also aims to develop a number of skills and attitudes to enable children to make better informed risk taking decisions. The packs are available to the teachers for the whole academic year. Teachers are asked to have addressed basic core elements, such as function of the heart and lungs, before the second stage - a hospital visit. In the study, packs were made available to all intervention schools for five months during which time the hospital visit also occurred. After use of the resource pack, the children visit a hospital where they are taught by IMPS trainers who have received special instruction. These children receive three learning opportunities:

(1) Basic life support and cardiopulmonary resuscitation skills training.

(2) A specially designed interactive video about common accidents demonstrating, for 
example, burns, cuts, electrocution, first aid responses.

(3) A tour of an accident and emergency department.

\section{SUBJECTS}

We adopted a non-randomised matched control design, using year 6 children in primary and middle schools. Randomisation could not be used because many schools were already enrolled in the programme. Instead, intervention and control schools were matched by location, size, and statutory assessment tasks. These are national curriculum assessment tests carried out at ages 7,11 and 14 years, the results of which are published in tables whereby schools performances/achievements are catalogued.

The control group was selected from schools that met the above criteria but had had no exposure to IMPS, either through invitation or application. The sample size needed was determined using the results of a previous pilot study. Using the child as the unit of analysis, a sample of 600 children in each group would be adequate to identify a $10 \%$ difference in knowledge, skills, attitude, and behaviour with $80 \%$ power at the 0.01 level of significance. Thus 1292 children were studied: 657 in the intervention group (12 schools) and 635 in the control group (15 schools).

We measured changes in each aspect of the child's performance in relation to knowledge, skills retention, attitude, and behaviour. All testing was done in schools five months after the intervention.

\section{MEASURES}

Knowledge was tested using a specifically developed quiz, which after coding into categories (correct, incorrect, missing, and not applicable) produced nominal level data. All children were tested before the intervention (to gain a baseline), and five months after intervention.

A hypothetical basic life support scenario was used to measure skill retention and behaviour. After intervention, each child was tested individually by one assessor. Their subsequent actions were scored by unblinded trained observers, on a score sheet that reflected Resuscitation Council guidelines. Interobserver error was minimised by use of a scenario "script".

Table 1 Safety knowledge: before and after intervention; results are mean (SD)

\begin{tabular}{|c|c|c|c|c|c|c|}
\hline \multirow[b]{2}{*}{ Safety quiz variable } & \multicolumn{2}{|c|}{ Intervention } & \multirow[b]{2}{*}{$\begin{array}{l}p \text { Value } \\
<0.01\end{array}$} & \multicolumn{2}{|l|}{ Control } & \multirow[b]{2}{*}{$\begin{array}{l}p \text { Value } \\
<0.01\end{array}$} \\
\hline & $\begin{array}{l}\text { Test1 } \\
(n=576)\end{array}$ & $\begin{array}{l}\text { Test } 2 \\
(n=542)\end{array}$ & & $\begin{array}{l}\text { Test1 } \\
(n=543)\end{array}$ & $\begin{array}{l}\text { Test } 2 \\
(n=554)\end{array}$ & \\
\hline Accidents in the home & $9.9(2.1)$ & $10.4(2.1)$ & + & $9.8(2.3)$ & $10.2(2.3)$ & + \\
\hline Electricity safety & $4.9(1.6)$ & $5.3(1.5)$ & + & $4.8(1.8)$ & $5.2(1.3)$ & + \\
\hline Safety skills & $4.4(1.1)$ & $4.5(1.0)$ & + & $4.2(1.1)$ & $4.3(1.1)$ & NS \\
\hline Fire safety & $3.6(1.0)$ & $3.7(1.0)$ & + & $3.5(1.0)$ & $3.7(1.0)$ & + \\
\hline Emergency 999 & $2.7(1.1)$ & $3.0(1.0)$ & + & $2.8(1.1)$ & $2.8(1.0)$ & NS \\
\hline Bicycle safety & $2.6(1.0)$ & $2.7(1.0)$ & NS & $2.6(1.0)$ & $2.8(1.0)$ & + \\
\hline Waterway safety & $2.3(1.3)$ & $2.6(1.1)$ & + & $2.3(1.2)$ & $2.6(1.0)$ & + \\
\hline Poisons recognition & $2.0(1.0)$ & $2.2(1.0)$ & + & $2.2(1.0)$ & $2.2(1.0)$ & NS \\
\hline Pedestrian safety & $1.8(1.9)$ & $2.6(2.2)$ & + & $2.3(2.2)$ & $2.7(2.1)$ & + \\
\hline Burns first aid & $1.3(1.0)$ & $1.5(1.0)$ & + & $1.1(1.0)$ & $1.3(1.0)$ & + \\
\hline Choking first aid & $1.2(1.0)$ & $1.6(1.0)$ & + & $1.2(1.0)$ & $1.3(1.0)$ & + \\
\hline
\end{tabular}

A validated investigative research tool, known as "draw and write", ${ }^{9}$ was used after intervention to measure attitudes and hypothetical behaviour towards safety. A specially produced video was shown, depicting an evolving story of a group of children engaged in both subtle and obviously dangerous activities near a canal. Children were required to record their observations and further develop the story by drawing and/or writing on a response sheet. The results were assessed by an independent observer, blind to school allocation.

In addition, evaluative questionnaires were sent to parents $(n=500)$ and teachers $(n=27)$ of children in the intervention group to determine how and if the IMPS programme influenced the children in their home and school environment.

\section{STATISTICAL ANALYSIS}

Statistical analysis was performed using SPSS for Windows. Tests included Mann-Whitney U, Wilcoxon matched pairs, Pearson's $\chi^{2}$, and the $\mathrm{z}$ test as appropriate for the distribution and nature of data. All $\mathrm{p}$ values are two tailed and the level of significance was taken as $<0.05$ or less.

\section{Results}

Initially, both groups demonstrated comparable levels of knowledge (table 1, test 1). Post-intervention testing (test 2) showed a statistically significant $(p<0.01)$ increase in knowledge in many of the areas for both groups. However, children exposed to IMPS demonstrated significantly greater knowledge than controls in three areas of safety that pertained specifically to the hospital component of the programme: calling 999, first aid for burns and for choking.

In relation to skills retention and behaviour, five months later children in the intervention group were more willing to undertake emergency life saving procedures, and significantly better than controls in almost all areas of basic life support (table 2). Curiously, controls were more likely to call an ambulance if the person was not breathing.

Differences in attitudes and behaviour were greatest in the observation of "subtle" (understated) dangers that were not explicitly presented in the video scenario (table 3). Based on the draw and write test, IMPS children were also more likely to tell others to stop doing something dangerous (table 4). Furthermore, had an accident occurred, intervention group children were more likely to respond by calling the emergency services.

Seventeen teachers (63\%) returned the questionnaire. Only three $(17.6 \%)$ delivered the entire resource pack. However, in $53 \%$ of the schools where IMPS was delivered, children had identified possible hazards around the school, such as uneven paving, broken glass, and syringes and changes had been implemented in $23 \%$ of these schools. Altogether $88 \%$ of teachers recorded that IMPS had been successful in raising children's awareness of safety issues. 
Table 2 Basic life support skills: five months after intervention; results are number (\%)

\begin{tabular}{lccc}
\hline Basic life support variables & $\begin{array}{c}\text { Intervention } \\
(n=534)\end{array}$ & $\begin{array}{l}\text { Control } \\
(n=581)\end{array}$ & $\begin{array}{c}p \text { Value } \\
<0.0005\end{array}$ \\
\hline Assessment of danger & $191(36)$ & $16(3)$ & + \\
Assessment of responsiveness & $312(58)$ & $68(12)$ & + \\
Call for help loudly & $140(26)$ & $54(9)$ & + \\
Assessment of airway & $90(17)$ & $20(3)$ & + \\
Assessment of breathing & $80(15)$ & $9(2)$ & + \\
Assessment of circulation/10 sec & $35(7)$ & $8(1)$ & + \\
\hline
\end{tabular}

Table 3 Identifying dangers: draw and write results; results are number (\%)

\begin{tabular}{lccc}
\hline Variable $^{*}$ & $\begin{array}{l}\text { Intervention } \\
(n=564)\end{array}$ & Control $(n=560)$ & $\begin{array}{l}p \text { Value } \\
<0.01\end{array}$ \\
\hline Electrocution risk & $102(18.1)$ & $40(7.3)$ & + \\
Toddler fall in water & $58(10.3)$ & $34(6.1)$ & + \\
Boy hurt going over wall/fence & $80(14.2)$ & $42(7.6)$ & + \\
Playing with a ball near water & $260(46.1)$ & $314(57.1)$ & + \\
General water danger & $58(10.3)$ & $82(14.9)$ & + \\
\hline
\end{tabular}

*What could go wrong?

Table 4 Stopping risky behaviour: draw and write results; results are number (\%)

\begin{tabular}{lccl}
\hline Draw and write variable & $\begin{array}{l}\text { Intervention } \\
(n=564)\end{array}$ & $\begin{array}{l}\text { Control } \\
(n=550)\end{array}$ & Significance level \\
\hline Don't walk over lock gate & $221(39.2)$ & $160(29.1)$ & $<0.01$ \\
Don't play near water & $141(25.0)$ & $98(17.8)$ & $<0.01$ \\
Don't play with magnifying glass & $30(5.3)$ & $13(2.4)$ & $<0.01$ \\
Don't use strimmer dangerously & $24(4.3)$ & $4(0.7)$ & $<0.01$ \\
Don't go near water & $58(10.3)$ & $89(16.2)$ & $<0.01$ \\
\hline
\end{tabular}

There was a response rate of $36 \%$ from the parents' questionnaire $(\mathrm{n}=180)$. Seventy four per cent (132) claimed that IMPS had raised their child's awareness of safety issues and 26\% (46) reported that their child had identified possible hazards around the home. These included toys on stairs, lack of smoke alarms, exposed wires, and permanently plugged in appliances. As a result 17.9\% (32) of parents reported having made changes in the home and $9 \%$ had helped others in danger-for example, a choking toddler, an unconscious adult, or assisting victims who had sustained broken limbs, lacerations, or burns. Most parents $(97 \%)$ indicated that IMPS should be taught in all schools.

\section{Discussion}

The results demonstrate that the combination of school didactic and hospital experiential learning used by the IMPS programme resulted in an increase in knowledge and skills, and changes in attitudes and behaviour. The results also suggest that the programme is successful in producing a limited but significant increase in knowledge. However, both groups showed a significant increase in knowledge in many of the areas tested. The reason for such similar results may be the natural maturation process. Alternatively, teaching "accident prevention" in the control schools may have contaminated the results, or teachers may even have increased what was normally taught, as they knew they were being assessed. A post-study questionnaire sent to control schools to identify the extent of other injury prevention related learning that had taken place during the study revealed that a number of schools had covered similar topics but these had been done piecemeal, often by external agencies.
Children attending the IMPS programme are taught the process of basic life support using an eight step sequence. It has been reported that many people, especially adults, find this technique difficult to acquire and easy to forget. ${ }^{10}$ Children who had completed IMPS were significantly more likely to attempt lifesaving procedures and to learn and retain basic life saving skills. However, at that time only $7 \%$ of IMPS trained children assessed the circulation before starting cardiac compressions. This omission may be due to the assessment of circulation appearing midpoint between two exciting physical skills, mouth-tomouth resuscitation and cardiac compressions. Also it is neither at the beginning nor at the end of the basic life support eight step sequence, both of which are salient features of serial recall. ${ }^{11}$ The Resuscitation Council UK has recognised the difficulty of the eight step sequence and suggest the emphasis be moved to "look for signs of circulation" when two initial breaths are administered. ${ }^{12}$

The results from the draw and write component of the study indicate that IMPS bought about a change in children's awareness, attitudes, and behaviour. This research tool gave the children a platform to voice their opinions about risks, accidents, and possible helping strategies. Significantly more IMPS children identified a greater number of potentially dangerous situations in the canal story. This may be interpreted as children translating their knowledge into an attitude that influences behaviour.

IMPS also had a beneficial effect on the home environment and teachers noted that after the programme children were more likely to point out potential hazards in and around the school.

\section{LIMITATIONS}

With hindsight, it would have been preferable to send similar questionnaires to parents and teachers of children in the control group to enable statistical measures of difference to be calculated. Teacher and parent comments, although extremely informative, were still subjective and therefore, of uncertain validity. Furthermore the low return rate of parent questionnaires due to teachers not having the resources to follow up, was likely to render the sample unrepresentative.

It is also important to consider the variations in the teaching in schools. Currently, as schools have discretion on delivery of the programme, children may not gain full exposure to the resource pack. Achieving sustained adherence to the recommended use may prove to be difficult. IMPS can only make recommendations and teachers have competing priorities and as it is not compulsory, it cannot be enforced. Finally, measures of school effects were not undertaken. These effects should be evaluated in a larger study.

\section{Implications for prevention}

Despite the limitations of this study, the results are encouraging for the provision of a pro- 
gramme based on a combination of didactic and experiential learning. This strategy resulted in a significant increase in children's knowledge and skills, and changes in their attitude and behaviour towards their own safety, the safety of others, and their awareness of their environment. The programme, integrated into the national curriculum, has been readily accepted by Oxfordshire schools. It is, however, too soon to estimate to what extent the programme has reduced the number or severity of injuries among children. IMPS has now received a grant from the government to set up three new centres in England and to investigate long term effectiveness. IMPS is free to schools but the programme costs approximately $£ 10$ per child.

We are grateful to Dr Helen Doll and Dr Paul Griffiths for assistance in analysis and interpretation of data, Mrs Margaret Collins for primary analysis of "draw and write", and to Mrs Collins for primary analysis of "dray

This work was undertaken by IMPS who received funding from the NHS Executive Anglia and Oxford; the views expressed in this publication are those of the authors and not necessarily those of the NHS Executive Anglia and Oxford.

1 Department of Health. Saving lives: our healthier nation. London: The Stationery Office, 1999.

2 Towner E, Dowswell T, Simpson G, et al. Health promotion in childhood and young adolescence for the prevention of unintentional injuries. London: Health Education Authority, 1996

3 tional injuries. London: Health Education Authority, 1996. dents. Primary health care group. London: Kings Fund Centre, 1987.

4 National Curriculum Council. Physical education nonstatutory guidance. London: HMSO, 1992.

5 Kemp A, Sibert J. Childhood accidents: epidemiology, Kemp A, Sibert J. Childhood accidents: epidemiology,
trends, and prevention. f Accid Emerg Med 1997;14:31620.

6 Maitra A. School accidents to children: time to act. 7 Accid Emerg Med 1997;14:240-2

7 Collins M. Risky business. Health Education 1992;May:1921

8 Department of Health. The health of the nation. A strategy for health in England. London: HMSO, 1992.

9 McWhirter JM, Wetton NM. Children's perceptions of risk. Fournal of Health and Safety 1994;10:21-9.

10 Moser DK, Coleman S. Recommendations for improving cardiopulmonary resuscitation skills retention. Heart Lung 1992;21:372-80.

11 Kagan J, Segal J. Psychology: an introduction. 6th Ed. Orlando, Florida: Harcourt Brace Jovanovich International Edition, 1988.

12 Resuscitation Council UK. Four-step CPR-improving skill retention. (Cited in Handley JA, Handley AJ.) Resuscitation retention. (Cited

\section{Are supermarkets a poisoning hazard?}

The NSW Health Department have just published the results of two surveys intended to establish whether poisonous products or products labelled "keep out of reach of children" were displayed for sale within reach of children. The first survey in 1994 followed an incident in which 21 month old in a shopping trolley was able to reach, open, and swallow some insecticidal dog wash, a life threatening poisoning event. The first survey (16 stores in the Hunter region) showed that all stores had items labelled "poison" or "keep out of reach of children" within one metre of the floor. This included the store at which the child was poisoned. The findings were communicated to the supermarket industry. A 1999 re-survey of a smaller number of stores in the same region, produced the same result. All stores had items within one metre of the floor. Just over one third of the products with "keep out of reach of children" labels, and within reach, did not have child resistant closures. While there have been isolated reports of poisoning, the authors report that current injury surveillance methods are unable to estimate the true burden of illness from such events. There is no legislation that regulates the placement of harmful substances or poisons in retail outlets (James and Williams, A new risk for children? NSW Public Health Bulletin, Vol 10, No 10, October 1999. www.health.nsw.gov.au/public-health/phb/phb.html).

Gun checks proposed

Los Angeles Times reporter Art Pine has been following efforts to strengthen gun control legislation in the US. One specific issue that has finally been resolved-at least at the Senate level - is the need for background checks on people buying firearms at gun shows. Another is the need for safety locks on all guns - an issue that was raised several years ago in this journal. 